\title{
Desigualdades territoriales y migración: consecuencias sociodemográficas y líneas de acción para la región Otomí- Tepehua (Hidalgo, México)
}

\author{
Alex Manetta \\ Universidad Autónoma del Estado de Hidalgo-México \\ ORCID: https://orcid.org/0000-0002-5558-0845 \\ Tomás Serrano Avilés \\ Instituto de Ciencias Sociales y Humanidades, Universidad Autónoma del Estado \\ de Hidalgo-México \\ ORCID: https://orcid.org/0000-0003-1116-7810
}

\begin{abstract}
Resumen
El artículo propone una contribución a los estudios sobre migración y desarrollo en la región Otomí-Tepehua (Hidalgo, México). Se reconoce una problemática que relaciona las características socio territoriales de la zona a la percepción de factores de expulsión de la población joven, lo que conlleva a una pérdida sistemática de la fuerza laboral y al refuerzo de las desventajas regionales comparativas. Con base en la investigación bibliográfica y cuantitativa, se realizó un diagnóstico que aporta la aplicación de la metodología del marco lógico, identificándose cuestiones-clave que direccionan líneas de acción para la mitigación de la emigración. De acuerdo a los resultados, solamente a través de la investigación, de la innovación, de la cooperación comunitaria e interinstitucional se puede alcanzar a estos objetivos. Sin embargo, este es un trabajo a ser realizado a lo largo plazo y que tiene que resolverse en ámbitos menos explorados de la política pública tradicional, como posibilidad de un desarrollo integral, participativo y sostenible.
\end{abstract}

Palabras-clave: Emigración. Pérdida de la fuerza laboral. Líneas de acción. Región OtomíTepehua.

Desigualdades territoriais e migração: consequências sócio demográficas e linhas de ação para a região Otomí-Tepehua (Hidalgo, México).

\section{Resumo}

O artigo propõe uma contribuição aos estudos sobre migração e desenvolvimento na região Otomí-Tepehua (Hidalgo, México). Reconhece-se um problema que relaciona as características sócio territoriais da área com a percepção de fatores de expulsão da população jovem, o que leva a uma perda sistemática da força de trabalho e ao reforço de desvantagens regionais comparativas. Com base na pesquisa bibliográfica e quantitativa, 
foi realizado um diagnóstico que permite a aplicação da metodologia do marco lógico, identificando-se os principais temas que direcionam as linhas de ação para a mitigação da emigração. De acordo com os resultados, somente por meio da pesquisa, da inovação, da cooperação comunitária e interinstitucional esses objetivos podem ser alcançados. No entanto, trata-se de um trabalho a ser realizado a longo prazo e que deve ser resolvido em áreas menos exploradas das políticas públicas tradicionais, como possibilidade de um desenvolvimento integral, participativo e sustentável.

Palavras-chave: Emigração. Perda de força laboral. Linhas de ação. Região Otomí-Tepehua.

Territorial inequalities and migration: socio demographic consequences and lines of action for the Otomí-Tepehua region (Hidalgo, Mexico).

Abstract

The article proposes a contribution to studies on migration and development in the OtomíTepehua region (Hidalgo, Mexico). A problem is recognize, that relates the socio-territorial characteristics of the area to the perception of expulsion factors of the young population, which leads to a systematic loss of the labor force and the reinforcement of comparative regional disadvantages. Based on the bibliographic and quantitative research, a diagnosis was made that provides the application of the logical framework methodology, identifying key issues that direct lines of action for the mitigation of emigration. According to the results, only through research, innovation, community and inter-institutional cooperation can be these objectives achieved. However, this is a job to make in the long term and that has to be resolved in less explored areas of traditional public policy, as a possibility of comprehensive, participatory and sustainable development.

Keywords: Emigration. Loss of workforce. Lines of action. Otomí-Tepehua Region.

\section{Introducción}

El desplazamiento de personas es parte integrante de la historia humana. Sus causas, características y consecuencias, sin embargo, se han diversificado a lo largo de la historia (DOMENACH; PICOUET, 1995). En lo que concierne a la migración, como aspecto particular de la movilidad humana, implica el cambio de residencia entre diferentes unidades político-administrativas (BILSBORROW, 1998), representando a uno de los componentes básicos de la dinámica demográfica. Desde las últimas décadas del siglo XX, en el ámbito de las caídas de las tasas de mortalidad y de fecundidad, la migración se convirtió en la principal fuerza que ha cambiado el ritmo de crecimiento, la estructura y la redistribución espacial de la población en los más diversas regiones del planeta (BELL et al., 2002).

En Latinoamérica el panorama de la migración ha sufrido profundas modificaciones. Si en períodos precedentes (1950-1980) los flujos de tipo ruralurbano predominaron y representaron el principal componente del proceso de urbanización, recientemente, con el aumento de la concentración urbana, son verificadas alteraciones en los principales flujos, creciendo en importancia los movimientos de tipo urbano-urbano (RODRÍGUEZ-VIGNOLI, 2002).

Concomitantemente, la migración campo-ciudad presentó una disminución relativa y absoluta (RODRÍGUEZ-VIGNOLI; BUSSO, 2009), desapareciendo, en México, como tema prioritario de atención política y académica (CAMPUZANO; CERQUERA, 2013; CANALES, 2006). 
A pesar del descenso de los flujos migratorios de tipo rural-urbano, en muchas zonas rurales de México la emigración con destino urbano es un proceso todavía relevante, ya que la salida sistemática de personas representa un significativo impacto sociodemográfico (RUIZ-CHAPETO, 2014), habiendo la necesidad de considerarse que estos procesos modifican las condiciones de vida tanto de la población que se va como de la que se queda (HERRERA, 2013).

Considerando la migración a partir de su dimensión espacial, o sea, desde las correlaciones entre el sentido de los flujos y las características de las localidades de origen y destino, se requiere una mirada hacia las desigualdades territoriales (BUSSO, 2009). En México se han profundizado las disparidades socio-espaciales, proceso ante lo cual las comunidades rurales e indígenas se encuentran en creciente desventaja (CASTLES; DELGADO-WISE, 2012). Como consecuencia se registra el seguimiento, aunque en menor intensidad, del proceso de desplazamiento de campesinos hacia las ciudades, al norte del país y a los Estados Unidos (DURAND; MASSEY, 2003).

En nivel interestatal, Hidalgo demuestra también un desarrollo bastante desigual, hecho evidenciado por la concentración de la población, de la prestación de servicios y de la producción agrícola e industrial en zonas específicas, mientras la mayor parte del estado se caracteriza por la dispersión demográfica, por la carencia de servicios y por la baja productividad agrícola. Este contexto ha motivado el seguimiento de los desplazamientos internos al estado, los movimientos con destino a otras entidades federativas y al exterior (HERNÁNDEZ, 2009; GUTIÉRREZ, 1992).

Las desigualdades socio territoriales son todavía más notables cuando analizadas por cortes étnicos y se han profundizado en las zonas donde históricamente se evidencian. Considerando a la región Otomí-Tepehua (Estado de Hidalgo, México), donde la población caracterizase por su condición rural, por elevados grados de marginación y evidentes rasgos indígenas (VARGAS-GONZÁLEZ, 2011), plantease acerca de los fenómenos que corroboran en su consolidación como zona originaria de flujos con destino urbano.

Se reconoce cuestiones particulares y de vital importancia para la región Otomí-Tepehua, donde la percepción de factores negativos conlleva a expectativas por mejores condiciones de vida a través de la emigración. El balance migratorio resultante conduce a la caída del crecimiento y a significativos cambios en la estructura demográfica, caracterizando una acentuada pérdida de población en edad laboral, lo que a su turno tiende al refuerzo de las desventajas territoriales comparativas. Ante esta coyuntura realizase un diagnóstico que aporta a la aplicación de la metodología del marco lógico, con el objetivo específico de definir líneas de acción para la mitigación de los graves problemas demográficos y socio ambientales detectados en la zona.

\section{Datos y métodos}

Se dedica un apartado inicial al enfoque teórico y conceptual que aporta a la elaboración del problema de estudio (Ítem 3). En seguida, presentase un diagnóstico centrado en la descripción de las principales características territoriales, sociales y demográficas de la región, planteándose como se interrelacionan. Para 
eso, realizase un trabajo de análisis de los indicadores de marginación (CONAPO, 2010) y de los impactos de la migración en la estructura demográfica regional, con enfoque en el proceso de pérdida de la población (Censos de Población y ViviendaINEGI, 2000 y 2010) (Ítem 4). Elaborado el diagnóstico, tratase de sistematizar los resultados a través de la metodología del marco lógico, con el propósito de direccionar la proposición de líneas de acción para la intervención pública y comunitaria. En este procedimiento, se determina un problema central, sus causas y sus efectos. A cada uno de los efectos les corresponde un fin, un medio y un eje de acciones, que deben conllevar a un objetivo común (Ítem 5). Al final, se presentan las conclusiones (Ítem 6) y las referencias.

\section{Marco teórico-conceptual y problema de investigación}

Admitiéndose que la relación entre desigualdades territoriales y la dirección de los flujos migratorios presenta vinculación con los factores que definen las fuerzas de atracción y de repulsión de la población, es cierto que las acciones que tengan como fin intervenir en este proceso deben de estar relacionadas con sus causas y con sus consecuencias. De esta forma, las acciones y programas de desarrollo territorial requieren integrar las migraciones en la definición de metas, considerando las características de los migrantes, la dirección de los flujos y los atributos de las localidades de origen y destino (BUSSO, 2009).

Desigualdades territoriales y migración

El territorio consiste en una fracción del espacio cuya delimitación depende de los aspectos tomados en cuenta, de modo que se define por la propia vigencia de procesos sociales, demográficos, políticos, culturales y económicos. Resulta de acciones conducidas por un conjunto de agentes al apropiarse de un fragmento del espacio total, ya sea de manera efectiva o a través de un proyecto. La producción de un territorio político, por ejemplo, demanda un espacio físico delimitado por fronteras y regido por una normatividad específica (RAFFESTIN, 1993), animado por circuitos espaciales productivos y por la población que ahí circula y se instala.

Con respecto al término región, consiste en una porción del territorio cuyos límites son dados por la vigencia de una funcionalidad interna. Por lo tanto, lo que distingue una región es el reconocimiento de una coherencia interna, cuya dinámica se vincula a procesos que van más allá de sus límites (SANTOS, 1996).

La región Otomí-Tepehua caracterizase como una porción del territorio hidalguense delimitada por límites municipales. Estos límites, sin embargo, están superpuestos a un orden que incluye dinámicas ambientales, económicas, sociales, culturales y demográficas concatenadas que revelan una coherencia interna característica de la zona, que representa un enorme potencial en términos de la movilización de recursos. Se plantea que a través de la investigación, de la cooperación, de la innovación y del ordenamiento territorial, sea posible activar recursos y capital social para la intervención en los factores que pesan en la decisión de emigrar.

El modelo push-pull incluí en el análisis de la migración una serie de aspectos relacionados a las localidades de origen y destino de los flujos. En cada localidad 
existen factores positivos y negativos que interactúan para mantener/atraer o para repeler/expulsar a las personas. Además, entre localidades de origen y destino, hay un conjunto de obstáculos intervinientes (costos, distancias, leyes o barreras físicas) cuya superación depende de las características de los migrantes (LEE, 1966).

Ya el modelo explicativo de Harris y Todaro (1970) aporta el supuesto de que migración desde el campo hacia a las ciudades está relacionada a las expectativas por mejores condiciones laborales en las ciudades. Sin embargo, aunque que el promedio del empleo urbano sea mejor pagado que el empleo rural, hay una probabilidad de que el migrante no encuentre una plaza de trabajo en contexto urbano y si acaso la encuentre tal vez el pago no sea tan atractivo. Además, es probable que haya un tiempo de espera hasta que se tenga una plaza de trabajo en el lugar de destino.

Tales hechos representan un desfase entre una situación real y situaciones esperadas, lo que conlleva a problemas sociales concentrados en contexto urbano, como el desempleo, la informalidad laboral y la caída en el ingreso promedio por la sobreoferta de mano-de-obra. Por otro lado, la población rural sufre con la emigración de sus jóvenes y con el mantenimiento de las condiciones de pobreza y marginación. Por eso, como parte de la resolución de problemas sociales en las ciudades, se propone la creación de empleos en el campo y la reducción del diferencial de los sueldos entre áreas rurales y urbanas (HARRIS; TODARO, 1970).

Bajo dichos modelos, buscase interpretar las relaciones entre las desigualdades territoriales, la percepción de factores de expulsión y la emigración laboral en la región Otomí-Tepehua, lo que conlleva al refuerzo de las desventajas regionales comparativas.

Migración, cambios en la estructura demográfica y refuerzo de las desventajas territoriales comparativas

México se encuentra en un período de profundas transformaciones, entre las cuales se destaca la transición demográfica. Por la caída en las tasas de mortalidad se observa un gradual incremento en la esperanza de vida al nacer. Simultáneamente, por efecto de la baja en las tasas de fecundidad, las cohortes tienden a ser cada vez más proporcionalmente reducidas. Como consecuencia, registrase una acentuada tendencia al envejecimiento poblacional (PARTIDA-BUSH, 2005).

El proceso de envejecimiento demográfico incluye una etapa caracterizada por el aumento de la población en edad laboral (15-64 años) y por la disminución proporcional de la población menor de 14 años, mientras el volumen de ancianos mayores a 65 años se incrementa lentamente. Como resultado hay un descenso temporario de la razón de dependencia $(\mathrm{RD})^{1}$, hecho que caracteriza el fenómeno denominado bono demográfico o ventana de oportunidades.

La caída de la RD representa un momento teóricamente ventajoso, cuando habría más personas trabajando con relación a sus dependientes, hecho que

\footnotetext{
1 La razón de dependencia representa la razón entre el volumen de la población dependiente (personas de 0 a 4 años + personas con 65 años y más) y el volumen de personas en edad laboral (1564 años).
} 
evidencia una tendencia a mejores condiciones sociales, tanto en nivel familiar como en niveles ampliados de análisis. A nivel macro, la reducción de la RD favorece el aumento del ahorro agregado y la generación de recursos disponibles para que se incrementen las tasas de inversión. A nivel familiar ocurre algo parecido, ya que la menor RD permite una acumulación de recursos y la inversión en capital humano y productivo (BRITO et al., 2008).

Sin embargo, para que el bono demográfico represente beneficios reales, es necesario que esté acompañado de inversión pública y privada en capital humano, en la cobertura educativa y por servicios de salud, con la oferta de trabajo formal y mejores pagos. Así que, en contextos de subdesarrollo, la abertura de esta ventana tiende a no encontrar el soporte necesario para su efectuación (BRITO et al., 2008).

Ante lo mencionado, se ubica la discusión de la pérdida del bono demográfico en la región Otomí-Tepehua, tanto por las malas condiciones sociales de los que se quedan como por la salida de los que se van.

Malas condiciones socioeconómicas, emigración y la pérdida de la ventana de oportunidades en la región Otomí-Tepehua

México se distingue en Latinoamérica por presentar menores niveles de desempleo juvenil. Sin embargo, la mayor parte de su mercado laboral caracterizase por la oferta de plazas informales y mal remuneradas. Ya sea por la falta absoluta de empleo o por el adelgazamiento del mercado de trabajo formal, se ha consolidado un agudo proceso de precarización laboral (OLIVEIRA, 2006).

En México, además de la pérdida de la ventana de oportunidades por las malas condiciones educativas y laborares, se registra una pérdida sistemática de la fuerza de trabajo por la emigración internacional, ya que son principalmente los jóvenes los que más emigran (CANALES, 2011). En este sentido, la emigración internacional, al presentarse en contra del bono demográfico mexicano, estaría en favor del bono demográfico estadounidense, país que recibe precisamente la mayor parte de estos emigrantes (LOZANO-ASCENCIO, 2003: 4).

En la región Otomí-Tepehua la emigración demuestra una caída entre los períodos 1995-2000 y 2005-2010 (véase el Ítem 4), pero, por su persistencia, presentase como factor sistemático de pérdida del bono demográfico. Pese a que se reconozcan dos factores de pérdida de la ventana de oportunidades, o sea, las malas condiciones socioeconómicas para los que se quedan y la pérdida de la población joven que se va, el presente análisis está centrado en el aspecto relacionado con la emigración.

\section{Territorio, población y tendencias recientes en la región Otomí-Tepehua}

Ubicada entre la Sierra Madre Oriental y el Altiplano del Valle de México, al sureste del Estado de Hidalgo, la región Otomí-Tepehua está integrada por tres municipios: Huehuetla, Tenango de Doria y San Bartolo Tutotepec (Figura 1). Colinda con el estado de Veracruz al norte y con el estado de Puebla al sur, ocupando una superficie total de aproximadamente $778,6 \mathrm{~km}^{2}$. Su topografía revela montañas y valles con altitudes que varían entre los 300 y $1.600 \mathrm{msnm}$, aspecto que le brinda una diversidad de climas predominantemente húmedos. 
Figura 1. Localización de la región Otomí-Tepehua.

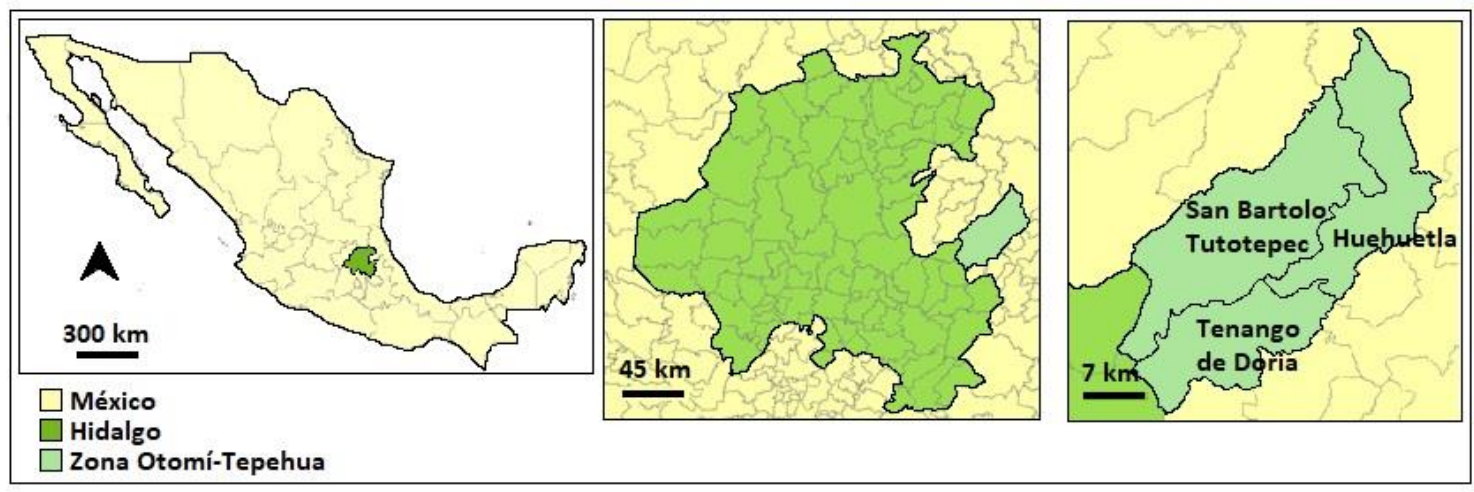

Fuente: elaboración propia con uso del Mapa Digital de México.

En la zona de estudio existe una significativa biodiversidad, reconocida como una de las más representativas del estado de Hidalgo, lo que abarca seis tipos principales de vegetación: bosque tropical perennifolio o selva; bosque mesófilo de montaña; bosque de encino; bosque de pino-encino y pastizal; vegetación acuática y subacuática; donde se encuentra también una variada fauna (VILLAVICENCIONIETO; PÉREZ-ESCANDÓN, 2010; RAMÍREZ-BAUTISTA et al., 2017).

La biodiversidad regional ha sido corrientemente retratada en un tipo de bordado llamado tenango, o bordado otomí, cuya manifestación se reconoce por la producción de verdaderas obras de arte textil (LORENZO-MONTERRUBIO, 2008).

En la Sierra Madre Oriental, por su geología, topografía, cobertura vegetal y pluviosidad, se ubican importantes manantiales de agua que originan ríos como el Pantepec, que al confluir con el río Vinazco ayuda a conformar el río Tuxpan, componiendo una de las más importantes cuencas hidrográficas de México (GRANADOS, 2008).

Aunque la zona se destaca por sus rasgos naturales, se observa un proceso de supresión de la vegetación original, hecho que repercute en la pérdida del hábitat para la fauna silvestre y en la destrucción de significativas extensiones de suelos, lo que conlleva a serios perjuicios a la prestación de servicios ambientales, a las actividades económicas y al mantenimiento de prácticas del conocimiento tradicional (MÉXICO. Comisión Nacional para el Conocimiento y Uso de la Biodiversidad, 2015; VILLAVICENCIO-NIETO; PÉREZ-ESCANDÓN, 2010).

En la región Otomí-Tepehua (2010) vivían cerca de 59,417 personas, la mayor parte en localidades rurales (90,8 \%), con una proporción significativa (22,8 \%) de hablantes de idiomas indígenas (CENSO DE POBLACIÓN Y VIVIENDA. Instituto Nacional de Estadística y Geografía, INEGI, 2010).

En dicha zona predominan los grupos étnicos que le dan nombre, o sea, otomíes y tepehuas, cuyos rasgos culturales más evidentes son el idioma y las vestimentas, incluyéndose a amplios sistemas de costumbres tradicionales que aún se mantienen (GÓMEZ-POMPA, 1993).

Cada uno de estos grupos presenta estrecha relación con la biodiversidad de su entorno, hecho registrado desde el siglo XVI por cronistas de Nueva España (MÁRQUEZ-RAMÍREZ, 2013). Esta relación siegue vigente tanto a través del uso alimentario de especies vegetales, nativas y cultivadas, como por el mantenimiento de prácticas terapéuticas, artesanales y culinarias (SÁNCHEZ-VÁZQUEZ, 2013). 
Por lo descripto, la zona ha sido señalada como área prioritaria para la conservación de sus características naturales y culturales (CABRERA et al., 2000)

A pesar de su reconocida riqueza cultural, en la región Otomí-Tepehua se presentan dificultades relativas a la transferencia intergeneracional de idiomas indígenas, conservándose, sobre todo, entre los adultos mayores, hecho que impacta en la pérdida de otros aspectos del conocimiento tradicional (GÓMEZ-AízA, 2013).

Evidenciase un contraste entre las riquezas biológicas y culturales de la zona y las condiciones de marginación ${ }^{2}$ en que vive la mayor parte de la población, principalmente en las comunidades rurales e indígenas, aspecto que revela su carácter ambivalente (GÓMEZ; VALTIERRA, 2005).

En este contexto, la marginación presentase como un factor negativo que potencializa tanto el ejercicio de la emigración como de la degradación ambiental, por el uso inadecuado, predatorio y no planeado de recursos (FONSECA, 2006).

La marginación es un fenómeno multidimensional de exclusión frente al proceso de desarrollo. Para medir su nivel el Consejo Nacional de Población construye índices que permiten diferenciar entidades federativas y municipios de acuerdo con las condiciones de educación, ingreso, vivienda y tamaño de las localidades (México. Consejo Nacional de Población, 2013).

El Cuadro 1 presenta la población total, el porcentaje de personas ocupadas que perciben ingresos de hasta dos salarios mínimos, los grados (GM) e índices absolutos de marginación (IAM), para los municipios de la región Otomí-Tepehua, Estado de Hidalgo y Estados Unidos Mexicanos (2010). Con referencia a los IAM los valores se presentan más elevados para los municipios de San Bartolo Tutotepec $(1,7)$ y Huehuetla $(1,4)$, lo que corresponde a grados de muy alta marginación. El índice de Tenango de Doria $(0,4)$ corresponde a un grado medio de marginación, mientras en nivel estatal este índice $(0,7)$ refleja a un alto grado de marginación.

Cuadro 1. Población total, porcentaje de ocupados que perciben ingresos de hasta dos salarios mínimos (\%), índice de absoluto de marginación (IAM) y grado de marginación (GM). Municipios de la región Otomí-Tepehua, Hidalgo y México (2010).

\begin{tabular}{|l|c|c|c|c|}
\hline & $\begin{array}{c}\text { Población } \\
\text { total }\end{array}$ & $\begin{array}{c}\text { Población } \\
\text { ocupada con } \\
\text { ingresos de hasta } \\
\text { dos salarios } \\
\text { mínimos }\end{array}$ & IAM & GM \\
\hline San Bartolo Tutotepec & 18.137 & 67,9 & 1,7 & Muy alto \\
\hline Huehuetla & 23.563 & 79,0 & 1,4 & Muy alto \\
\hline Tenango de Doria & 17.206 & 65,7 & 0,4 & Medio \\
\hline Hidalgo & $\mathbf{2 . 6 6 5 . 0 1 8}$ & $\mathbf{4 9 , 3}$ & $\mathbf{0 , 7}$ & Alto \\
\hline México & $\mathbf{1 1 2 . 3 3 6 . 5 3 8}$ & $\mathbf{3 8 , 7}$ & $*$ & $*$ \\
\hline
\end{tabular}

* Por cuestiones metodológicas, el nivel nacional no cuenta con el IAM calculado.

Fuente: ÍNDICE ABSOLUTO DE MARGINACIÓN. Consejo Nacional de Población (2010).

\footnotetext{
${ }^{2}$ Para el cálculo de índices de marginación, el CONAPO se utiliza de datos secundarios del INEGI (Censos de Población y Vivienda, Conteos y Encuestas), considerando aspectos relativos a las dimensiones educativa, condiciones de vivienda y disponibilidad de bienes.
} 
Aunque la municipalidad de Tenango de Doria haya presentado mejor IAM que la entidad federativa, tomándose en cuenta algunos rubros específicos que componen el índice de marginación, se puede notar las desventajas que los municipios de la zona presentan frente a los niveles estatal y nacional, demostrando mayores rechazos en las condiciones educativas, de vivienda y de ingreso. Con referencia al porcentaje de personas ocupadas con ingreso menor a dos salarios mínimos (2010), los valores se presentan más elevados para Huehuetla (79,0\%), San Bartolo Tutotepec $(67,9 \%)$ y Tenango de Doria (65,7\%), mientras Hidalgo alcanzó a los 49,3\% y México los 38,7\% (Cuadro 1).

El Gráfico 1 demuestra mayor rechazo también en las condiciones educativas de la población con 15 años y más en los municipios de la zona Otomí-Tepehua, comparativamente a los niveles estatal y nacional (2010). Los porcentajes de analfabetos y de personas sin educación primaria completa se presentan más elevados en San Bartolo Tutotepec (34,3 y 51,6\%, respectivamente) y Huehuetla (33,5 y 50,8\%). El municipio de Tenango de Doria presenta también importante rechazo educativo ( $23,4 \%$ de analfabetos y $41,5 \%$ de personas sin primaria completa), pero en menor intensidad que sus vecinos. Ya a nivel estatal y nacional el rechazo educativo es aún elevado, pero menos intenso, con relación tanto al analfabetismo (10,3\% en Hidalgo y $6,9 \%$ en México) como al porcentaje de personas sin primaria completa ( $22,7 \%$ y $19,9 \%$, respectivamente).

Gráfico 1. Población con 15 años y más analfabeta y sin primária completa. Municipios de la región Otomí-Tepehua, Hidalgo y México (2010)

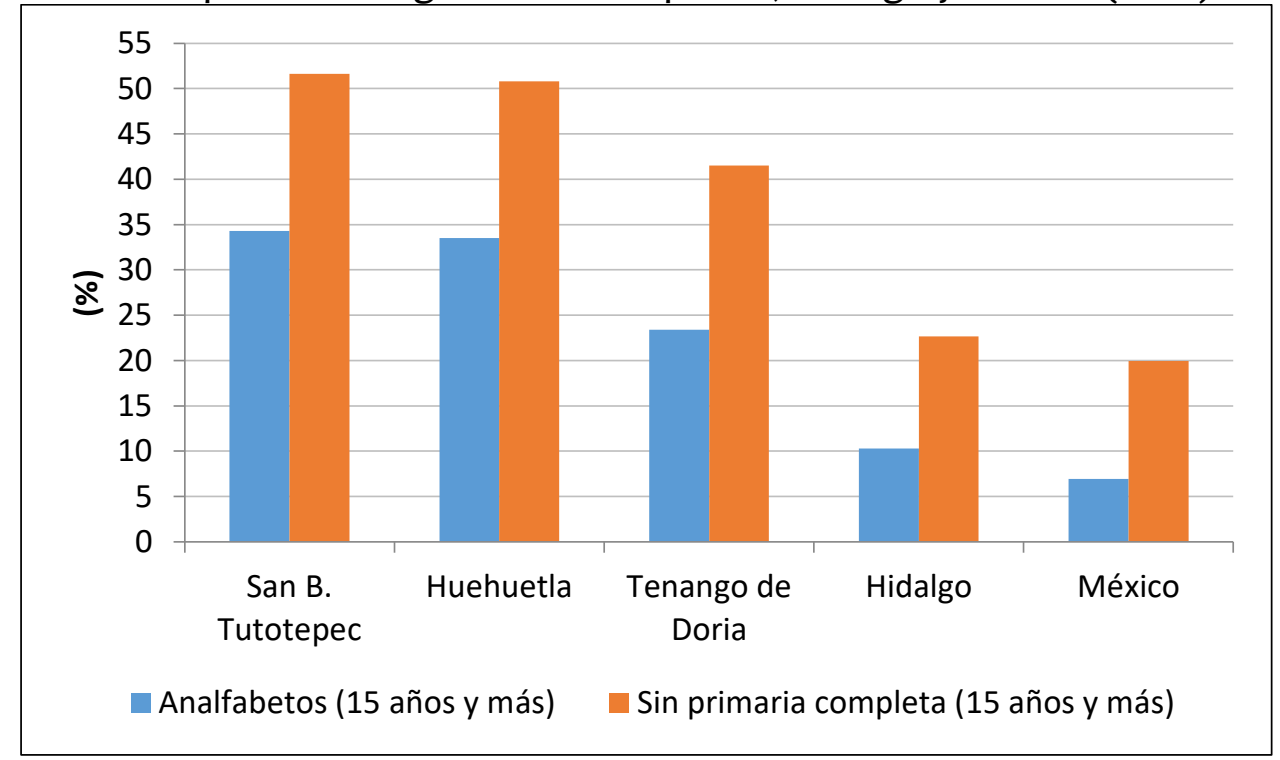

Fuente: ÍNDICE ABSOLUTO DE MARGINACIÓN. Consejo Nacional de Población (2010).

En lo que toca a las condiciones de vivienda (2010), se nota elevados porcentajes de personas que viven sin servicios públicos básicos, en todos los niveles administrativos. Huehuetla alcanza a los $47,3 \%$ de la población sin agua entubada y a los 8,6 \% sin servicio sanitario, mientras San Bartolo Tutotepec presenta los 33,7 y $12,5 \%$ y Tenango de Doria los 14,0 y $5,3 \%$, respectivamente. En nivel estatal se registra $9,1 \%$ sin agua entubada y $6,0 \%$ sin servicio sanitario. A nivel nacional, de modo respectivo, estos valores corresponden a los 8,6 y 3,6\%. Los 
porcentajes de personas en viviendas sin energía eléctrica y con pisos de tierra son también significativos, sobretodo en nivel municipal. San Bartolo Tutotepec $(22,1 \%)$ y Huehuetla (10,0\%) presentan mayor rechazo en el acceso a la energía eléctrica, mientras Tenango de Doria $(4,4 \%)$ se acerca más a los indicadores estatales $(2,5 \%)$ y nacionales $(1,8 \%)$. Con relación al porcentaje de ocupantes en viviendas con piso de tierra, S. B. Tutotepec presenta mayor rechazo $(28,1 \%)$, mientras Huehuetla $(8,5 \%)$ y Tenango de Doria (5\%) se acercan más a los niveles estatal $(7,2 \%)$ y nacional $(6,6 \%)$ (Gráfico 2).

Gráfico 2. Población ocupante de viviendas sin servicio sanitario, sin energia eléctrica, sin agua entubada y con piso de tierra (2010)

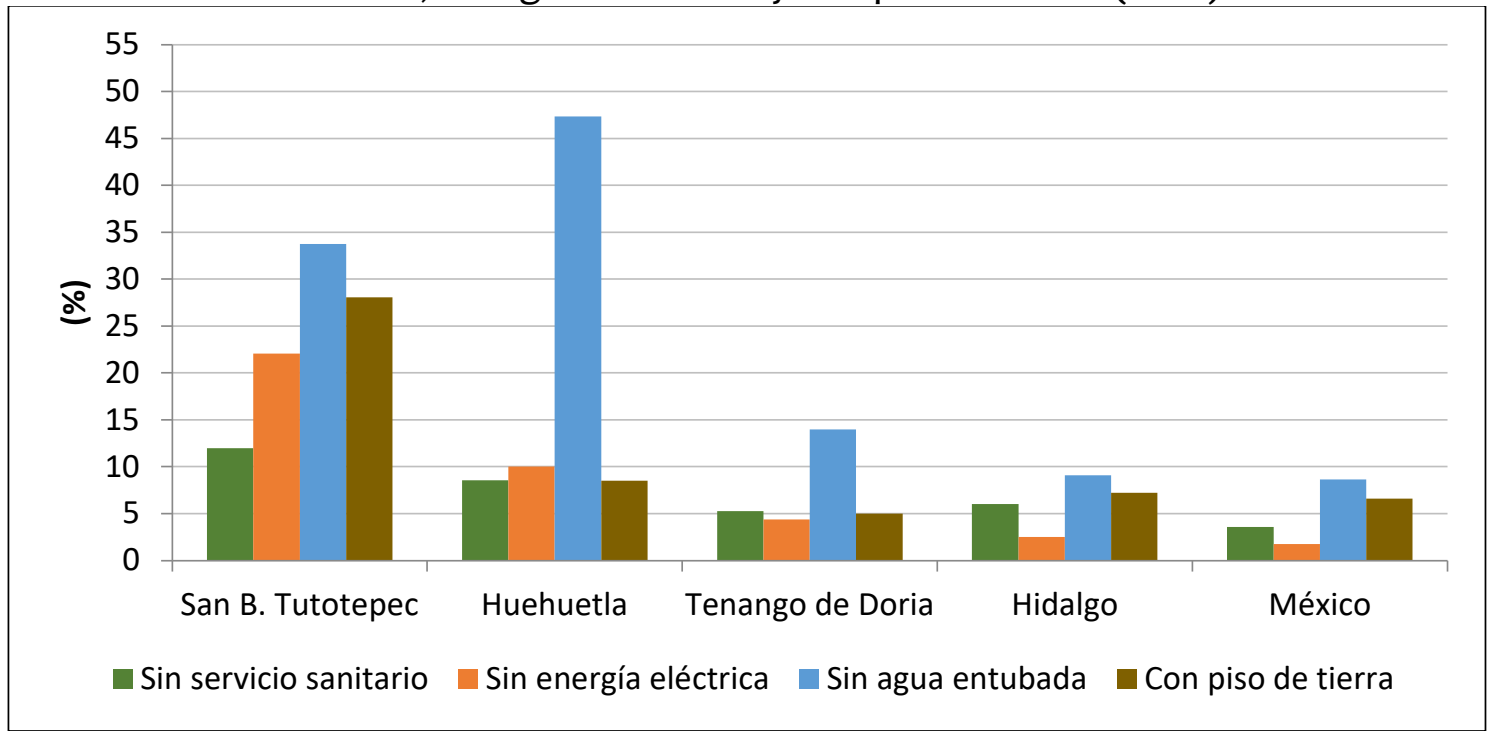

Fuente: ÍNDICE ABSOLUTO DE MARGINACIÓN. Consejo Nacional de Población (2010).

Los componentes del IAM (2010) reflejan la condición de vulnerabilidad bajo la cual se vive en la región Otomí-Tepehua y sus diferencias a nivel municipal. Los elevados porcentajes de ocupados con ingreso de hasta dos salarios mínimos se relacionan a la baja capacitación de los trabajadores y con una baja capacidad para adquirirse bienes y servicios. La escasa o nula escolaridad repercute en la productividad e innovación del trabajo colectivo, con impactos también en las oportunidades individuales de movilidad social. Las malas condiciones del domicilio dificultan las labores domésticas y tienen impacto sobre la higiene y la salud de sus ocupantes, propiciando la transmisión de enfermedades gastrointestinales, entre otras, que pueden convertirse en problemas de salud pública, aumentando las disparidades sociales y afectando a la calidad de vida (MÉXICO. Consejo Nacional de Población, 2013).

Los IAM son utilizados por las diversas instancias gubernamentales de México como parámetros para la identificación de localidades y poblaciones a ser priorizadas por los programas públicos de enfrentamiento de la pobreza. Si bien la política social ha buscado compensar el deterioro en las condiciones de vida en las localidades marginadas, su alcance ha sido insuficiente, en la medida que fue pensada como un modelo asistencial direccionado a poblaciones-objetivo, bajo el privilegio de la política económica y de los rigurosos límites presupuestales vinculados al PIB nacional (TORRES; ROJAS, 2015). 
En México la estrategia económica de industrialización substitutiva de las importaciones fue el principal motor de la economía en mediados del siglo pasado, lo que conllevó al aumento de las desigualdades sociales y de las desventajas rurales comparativas. Ya a partir de los años 1980, el país implementó el modelo de crecimiento económico basado en la apertura comercial, cuya exclusividad, otorgada a las actividades de exportación, impactó aún más a las disparidades regionales, con crecientes perjuicios a la población rural (GÓMEZ-OLIVER; TACUBASANTOS, 2017).

Desde los años 1980, diversos programas para la mitigación de la pobreza y de la desigualdad fueron realizados, como el Pronasol, el Progresa, el Oportunidades y el Prospera, cuyo objetivo fue la atención a las necesidades más apremiantes en materia de alimentación, vivienda, educación y salud, planteándose también acerca de la mejoría de la infraestructura agropecuaria rechazada y de la formación del capital humano en comunidades marginadas. Sin embargo, como se mantuvo un esquema de beneficios asistenciales destinados a poblaciones-objetivo, en la práctica esta política ha dejado afuera a una elevada proporción de personas en situaciones de vulnerabilidad (TORRES; ROJAS, 2015).

No obstante el crecimiento anual promedio del $2 \%$ al año del gasto público social, las condiciones de los mexicanos no han mejorado (2005-2014), evidencia de que los programas públicos no han ofrecido la oportunidad para que las nuevas generaciones salgan de la pobreza. Tampoco hay evidencias de mejorías en el estancamiento productivo de áreas rurales (CORTE-CRUZ; CARRILLO-HUERTA, 2017). Frente estas constataciones, necesitase una transformación de la política económica orientada por el modelo neoliberal y de su correspondiente política social, pues, de lo contrario, los costos a la población seguirán incrementándose (TORRES; ROJAS, 2015).

Con relación específica a al estado de Hidalgo y a la región Otomí-Tepehua, son escasos los estudios publicados sobre las políticas sociales implementadas y sus resultados. Sin embargo, es posible sostener que su impacto no ha sido suficiente para reverter la situación predominante de pobreza y vulnerabilidad social. Aunque hubo avances logrados en términos de las políticas sociales formales, es necesario enfatizar la limitada capacidad técnica y administrativa de los municipios al efectuaren los planes - municipales, estatal y nacional - de desarrollo, ya que es justo a este nivel que las acciones deben de ser efectivamente planeadas, gestionadas y aplicadas (MANETTA; HERNÁNDEZ; SERRANO, 2017). Tales hechos han conllevado al fracaso de acciones emprendidas y al desperdicio de recursos (GARCíA, 2019), eso sin mencionarse a la ocurrencia de usos indebidos y falta de transparencia en la gestión del dinero público destinado a programas sociales, lo que revela la mala administración y prácticas frecuentes de corrupción (HUERTA, 2014).

A pesar de las condiciones de marginación, de la escasa atención gubernamental y de la gradual pérdida del conocimiento tradicional, los habitantes de la región Otomí-Tepehua han logrado subsistir gracias al aprovechamiento de los recursos de su entorno (VILLAVICENCIO-NIETO; PÉREZ-ESCANDÓN, 2010). Por tratarse de un contexto predominantemente rural, la mayor parte de la población encuentra ocupación y subsistencia en actividades agropecuarias, principalmente en la producción del café de sombra. Sin embargo, la inestabilidad internacional en 
los precios del café ha generado consecuencias negativas en la dinámica socio económica regional (PÉREZ, 2002).

Los cambios del valor del café han afectado directamente a los empleados y pequeños productores agrícolas. Además, se reconocen otros aspectos críticos para la rentabilidad económica de este tipo de cultivo en la zona: la carencia de vías de transporte y de comercialización adecuadas; la falta de maquinaría para beneficio; la falta de organización de los productores; la heterogeneidad en la calidad final del producto; la falta de políticas públicas sectoriales y el escaso financiamiento (SALAZAR-ORTIZ; SILVA; BASURTO-PEÑA, 2013).

Con referencia a los programas públicos sectoriales de aporte a la producción del café, se puede mencionar el desmantelamiento de instituciones que fomentaban su desarrollo. Con el cierre de la Aseguradora Nacional Agrícola y Ganadera (ANAGSA-1990), del Instituto Mexicano del Café (INMECAFÉ-1991), de la industria Fertilizantes Mexicanos (FERTIMEX-1992), del Banco Nacional de Crédito Rural (BANRURAL-1995) y del Programa Nacional de Semillas (PRONASE-2002), se abrió paso a la privatización del servicio de asesoría técnica y de concesión de crédito a la producción, apoyos necesarios al combate a las desigualdades en el sector agropecuario. Así que la situación prevaleciente en las comunidades indígenas cafetaleras pasó a estar marcada por la falta de atención de los niveles federales del gobierno, bajo el dogma neoliberal del mercado auto regulado, lo que ha conducido a un estancamiento de la economía regional y al crecimiento de la pobreza y de las desigualdades (ROMO; PEREZ, 2018).

A pesar de las dificultades enfrentadas por los productores, el café de sombra suele ser producido mediante dos distintos métodos: el monocultivo, cuando el café es cultivado bajo la sombra de bosques originales; y el policultivo, cuando la sombra es dada por árboles como el mango o la pimenta. En la sierra Otomí-Tepehua predomina el monocultivo. En Huehuetla, en un conjunto de 15 huertas, se registró 79 especies leñosas de árboles y arbustos de 40 familias botánicas diferentes, la mayoría especies nativas, de modo que los cafetales se constituyen significativos reservatorios de biodiversidad (SALAZAR-ORTIZ; SILVA; BASURTO-PEÑA, 2013).

La mayor o menor riqueza de especies albergadas en los cafetales se relaciona con la filiación étnica de sus propietarios. Se registró mayor diversidad correspondiente a los cultivos de los otomíes en comparación a los cultivos de los tepehuas o mestizos, justo por los diferentes usos que le dan a las especies vegetales. Al beneficio brindado por el autoconsumo y por la venta del café, se suma la obtención de una serie de bienes que contribuyen al bienestar de las familias y de su entorno, ya que el bosque les brinda alimentos, leña, madera, medicinas y sombra, mantiene sano el suelo, regula el flujo hídrico, produce oxígeno y captura gas carbónico de la atmósfera (SALAZAR-ORTIZ; SILVA; BASURTO-PEÑA, 2013).

El cultivo del café de sombra está directamente relacionado a la conservación de la biodiversidad y a la manutención de los servicios ambientales en la zona Otomí-Tepehua. Sin embargo, debido a presiones externas, la población ha cambiado sus formas tradicionales de producción por milpas y pastizales, lo que ha intensificado la tala de los bosques y el deterioro de los ecosistemas. Por eso, existe un tipo de presión ejercida por entidades gubernamentales, no-gubernamentales y 
académicas, que requieren el establecimiento de áreas de protección ambiental, lo que hace que hayan pobladores, políticos y empresarios preocupados con las normas de restricción del uso del suelo, lo que conlleva a conflictos sociales (GÓMEZ-AíZA, 2013).

Para allá de estos problemas coyunturales, durante la plática con ciudadanos y administradores municipales se reconoció la escasa organización social como otra de las causas principales del atraso observado en los sectores productivos de la zona, aspecto que no permite un aprovechamiento adecuado de los recursos regionales, limitándose el desarrollo individual, familiar y comunitario.

Es evidente, por lo tanto, que en la zona Otomí-Tepehua la problemática regional pasa por hechos como: la falta de organización comunitaria, las dificultades de producción y venta del café, la baja remuneración al trabajo, la ineficacia de programas públicos, la insuficiencia de servicios básicos y el proceso de cambio en el uso del suelo, con severas pérdidas del conocimiento tradicional y en la prestación de servicios ambientales. A esto se suman las limitadas posibilidades de inserción educativa y la emigración laboral.

Migración y cambios en la estructura de la población

En el año 2000 vivían alrededor de 60.728 personas en la región OtomíTepehua, mientras en al año 2010 se registró un total de 59.417 habitantes, hecho que corresponde a un decrecimiento medio de 0,2 (\%) al año (2000-2010). En las dos Fechas evaluadas se registró mayor volumen de mujeres, hecho evidenciado por la razón ${ }^{3}$ de sexo (102,6 y 102,5, en 2000 y 2010, respectivamente) (CENSOS DE POBLACIÓN Y VIVIENDA, 2000 y 2010). En un contexto de elevada fecundidad ${ }^{4}$ y de una sobre mortalidad masculina no muy acentuada, se infieren los impactos de la emigración predominantemente joven y masculina, en el balance demográfico de la de la zona.

De hecho, durante las últimas décadas, la zona Otomí-Tepehua ha sido caracterizada como un área de expulsión de población. Una comparación de los datos referentes a la migración en dos períodos (1995-2000 y 2005-2010), revela que la intensidad de la inmigración se mantuvo entre las dos etapas (4,6 y 4,7 inmigrantes para cada mil personas, respectivamente). Sin embargo, la intensidad emigratoria disminuyó significativamente (de 33,2 a 12,8 emigrantes para cada mil personas), baja que ocurrió más por una caída en la emigración interna a México que por alteraciones en la intensidad de la emigración con destino internacional (Cuadro 2).

\footnotetext{
${ }^{3}$ La razón de sexo representa el número de mujeres por cada 100 hombres, de modo que los valores mayores a cien reflejan mayoría femenina mientras valores menores a cien indican mayoría masculina.

${ }^{4}$ En el período 1999-2001, la tasa global de fecundidad de la zona Otomí-Tepehua fue de 3,7 hijos por mujer al final de su vida reproductiva, mientras en el período 2005-2009 este promedio bajó para 3,0 (VÁZQUEZ-SANDRÍN, 2018).
} 
Cuadro 2. Volúmenes de migrantes, saldos migratorios netos, índices de eficacia migratoria (IEM), tasas de inmigración y de emigración. Región Otomí-Tepehua

(1995-2000 y 2005-2010).

\begin{tabular}{|l|c|c|}
\hline & $\mathbf{1 9 9 5 - 2 0 0 0}$ & $\mathbf{2 0 0 5 - 2 0 1 0}$ \\
\hline Inmigrantes & 1.421 & 1.401 \\
\hline Emigrantes internos & 8.782 & 2.678 \\
\hline Emigrantes internacionales & 1.361 & 1.133 \\
\hline Emigrantes (Total) & $\mathbf{1 0 . 1 4 3}$ & $\mathbf{3 . 8 1 1}$ \\
\hline Saldo neto migratorio & $\mathbf{- 8 . 7 2 2}$ & $\mathbf{- 2 . 4 1 0}$ \\
\hline IEM & $-\mathbf{0 , 8}$ & $-\mathbf{0 , 5}$ \\
\hline T. INM (1,000 personas) & $\mathbf{4 , 6}$ & $\mathbf{4 , 7}$ \\
\hline T. EMI (1,000 personas) & $\mathbf{3 3 , 2}$ & $\mathbf{1 2 , 8}$ \\
\hline
\end{tabular}

Fuente: elaboración propia a partir de datos de los CENSOS DE POBLACIÓN Y VIVIENDA, 2000 y 2010.

A pesar de una caída en su intensidad, la emigración interna sigue todavía más intensa que la emigración internacional. A esto respecto Villavicencio-Nieto y Pérez-Escandón (2010) argumentan que, por falta de recursos suficientes para cubrir el costo del viaje, la mayoría de los emigrantes originarios de la zona OtomíTepehua se desplaza internamente al país, en búsqueda de inserción laboral y mejores oportunidades en contexto urbano.

En los períodos 1995-2000 y 2005-2010, el balance migratorio conllevó a saldos migratorios negativos de $-8,722$ y $-2,410$ personas, lo que corresponde a índices ${ }^{5}$ de eficacia migratoria de $-0,8$ y $-0,5$, respectivamente. Estos resultados demuestran una zona de circulación migratoria con pérdida poblacional, siendo esta pérdida más severa en el primer período (1995-2000) (Cuadro 2).

De acuerdo a los datos disponibles (Gráfico 3), la pérdida poblacional provocada por los movimientos migratorios se presenta selectiva en términos de sexo y edad, siendo más intensa entre hombres y personas en edad laboral. Además, aunque el saldo negativo haya representado un volumen relativamente reducido en el segundo período (2005-2010), comparativamente al período anterior (1995-2000), estuvo proporcionalmente más concentrado en edades laborales (15 a 64 años) (Cuadro 3).

\footnotetext{
${ }^{5}$ El índice de eficacia migratoria es cociente entre la migración neta (I-E) y la migración bruta (I+E). Valores próximos a 1 indican áreas de alta atracción migratoria, valores próximos a - 1 indican áreas de alta expulsión migratoria, valores próximos a o indican áreas caracterizadas por la circulación migratoria (inmigración en niveles parecidos a la emigración).
} 
Gráfico 3. Distribución del volumen de saldo migratório negativo por sexo y grupos de edades. Región Otomí-Tepehua (1995-2000 y 2005-2010)

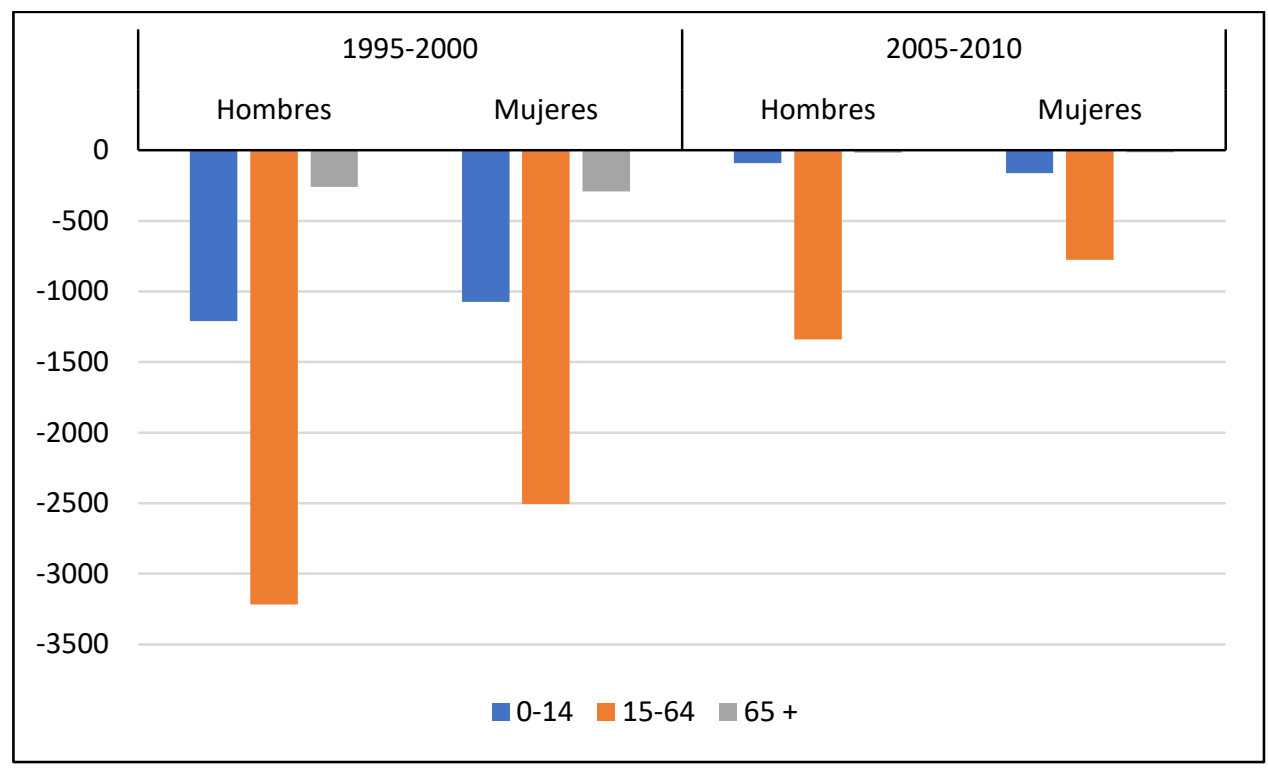

Fuente: elaboración propia a partir de datos del CENSO DE POBLACIÓN Y VIVIEND, 2000 y 2010.

Cuadro 3. Distribución porcentual del saldo migratorio negativo por sexo y grupos de edad. Región Otomí-Tepehua (1995-2000 y 2005-2010)

\begin{tabular}{|l|c|c|c|c|}
\hline \multirow{2}{*}{} & \multicolumn{2}{|c|}{$1995-2000$} & \multicolumn{2}{c|}{ 2005-2010 } \\
\cline { 2 - 5 } & Hombres & Mujeres & Hombres & Mujeres \\
\hline $\mathbf{0 - 1 4}$ & 14,1 & 12,5 & 3,7 & 6,8 \\
\hline $\mathbf{1 5 - 6 4}$ & 37,6 & 29,3 & 55,9 & 32,4 \\
\hline $\mathbf{6 5 +}$ & 3,0 & 3,4 & 0,6 & 0,5 \\
\hline Total por sexo & $\mathbf{5 4 , 8}$ & $\mathbf{4 5 , 2}$ & $\mathbf{6 0 , 3}$ & $\mathbf{3 9 , 7}$ \\
\hline Total & \multicolumn{3}{|c|}{$100, \mathbf{0}$} & \multicolumn{2}{c|}{$100, \mathbf{0}$} \\
\hline
\end{tabular}

Fuente: elaboración propia a partir de datos del CENSO DE POBLACIÓN Y VIVIENDA, 2000 y 2010.

Ya que son los jóvenes y adultos en edad laboral los que emigran en mayor intensidad, la migración tiene efectos significativos en la dinámica sociodemográfica del área de estudio, en específico, en lo que toca a los impactos en la estructura por sexo y edad de la población.

La estructura demográfica muestra una evidente diferencia proporcional de la población en edad laboral por sexo (2000 y 2010), destacándose una mayor proporción de personas del sexo femenino (Gráfico 4), lo que corresponde al hecho de que los hombres en este grupo componen la mayor proporción del saldo migratorio negativo (2000 y 2010). Es evidente que el diferencial de la mortalidad por sexo podría resultar en una mayor proporción de mujeres en edad activa en la población total. Sin embargo, no hay evidencias de una sobre mortalidad masculina tan acentuada en la zona (México. Instituto Nacional de Estadística y Geografía, Registros Administrativos de Defunciones, 1995-2000 y 2005-2010), de modo que tales resultados son atribuidos al proceso migratorio. 
Gráfico 4. Distribución porcentual de la población por sexo y grupos de edade. Región Otomí-Tepehua (2000 y 2010)

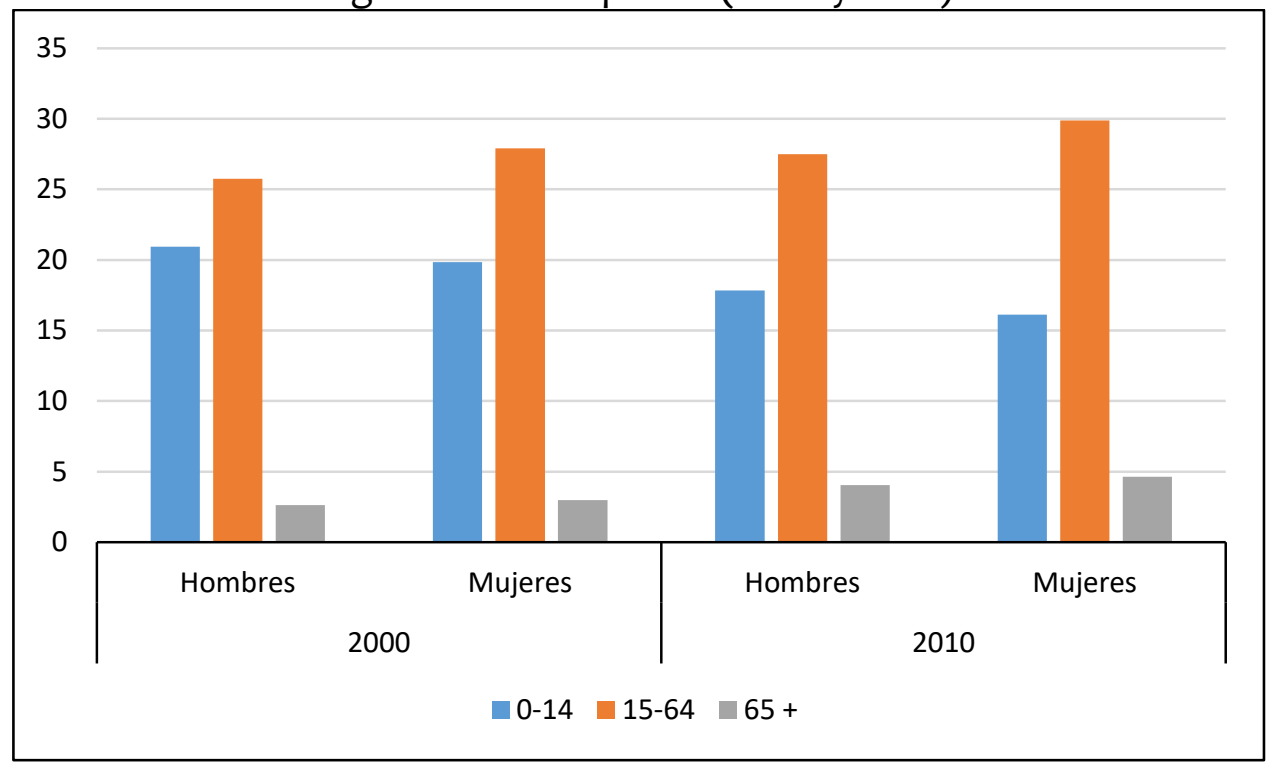

Fuente: elaboración propia a partir de datos del CENSO DE POBLACIÓN Y VIVIENDA, 2000 y 2010.

Con referencia en el Gráfico 4, entre los períodos evaluados (1995-2000 y 2005-2010) hubo una disminución proporcional de la población infantil (0-14 años) de ambos sexos, como resultados de la disminución en las tasas de fecundidad, mientras se incrementó la proporción de personas en edad laboral (15-64 años) y de adultos mayores a los 65 años.

Los cambios en la estructura demográfica conllevan a una disminución de la razón de dependencia (RD) para ambos sexos (2000 y 2010), hecho considerado una ventaja según el punto de vista de la ventana de oportunidades. Sin embargo, la RD podría representar valores aún más bajos si no fuera por los saldos migratorios negativos concentrados en las personas con edad laboral. Por eso, se realizó un ejercicio para estimar la RD con el escenario de saldos migratorios nulos para ambos períodos evaluados (1995-2000 y 2005-2010). Los resultados demuestran RD estimadas más bajas que RD registradas, sobre todo para el sexo masculino, lo que coincide con el argumento que vincula la emigración con la pérdida sistemática de la ventana de oportunidades (Cuadro 4).

Cuadro 4. Razón de dependencia (RD) observada, razón de dependencia (RD) estimada y tasa de variación porcentual (Var. \%) por sexo. Región Otomí-Tepehua (2000 y 2010)

\begin{tabular}{|l|c|c|c|c|}
\hline \multirow{2}{*}{} & \multicolumn{2}{|c|}{2000} & \multicolumn{2}{c|}{2010} \\
\cline { 2 - 5 } & Hombres & Mujeres & Hombres & Mujeres \\
\hline RD registrada & 0,91 & 0,82 & 0,80 & 0,69 \\
\hline RD estimada & 0,84 & 0,78 & 0,76 & 0,69 \\
\hline Var. (\%) & $-\mathbf{8 , 1}$ & $-\mathbf{4 , 5}$ & $-\mathbf{5 , 0}$ & $-\mathbf{- 0 , 5}$ \\
\hline
\end{tabular}

Fuente: elaboración propia a partir de datos del CENSO DE POBLACIÓN Y VIVIENDA, 2000 y 2010. 
Las condiciones de marginación de los jóvenes y adultos residentes en la zona representan un segundo factor de pérdida del bono demográfico, ya que las ventajas de un aumento en el volumen y en la proporción personas en edad laboral no han sido aprovechadas, configurándose situaciones de refuerzo a los factores de expulsión de la población a través de un círculo vicioso. Son destacadas, por lo tanto, las demandas por acciones y proyectos de desarrollo capaces de mitigar las desventajas regionales comparativas.

\section{Lineamientos para la proposición de acciones de intervención en la región Otomí- Tepehua}

Según Merino (2009), las limitadas oportunidades de integración laboral para la población rural mexicana se relacionan con la indefinición de los principales problemas públicos a resolver, de modo que para una efectiva intervención necesitase un diagnóstico y un plan de acciones basado en conocimientos sistemáticamente estructurados (RODRÍGUEZ, 2001, p. 13; SUBIRATS et al., 2008).

Con la finalidad de aportar la proposición de líneas de acción direccionadas al enfrentamiento de problemas detectados en el diagnóstico de la zona OtomíTepehua, se realizó la aplicación de la metodología del marco lógico, procedimiento que considera un problema central, sus causas y sus efectos. A cada uno de los efectos les corresponde un fin, un medio y un eje de acciones, que deben conllevar a un objetivo común (ORTEGÓN; PACHECO; PIETRO, 2005).

La Figura 2 contiene la descripción de los diferentes elementos que componen la aplicación del marco lógico al caso particular de la zona OtomíTepehua y representa sus interrelaciones. El problema central está enfocado en las escasas oportunidades de integración económica para la población en edad laboral. Como causas de este problema, se reconoce: 1) la deficiente organización y participación comunitaria; 2 ) la falta de innovación con relación a las actividades productivas, prestación de servicios, uso y gestión de los recursos naturales; 3) la deficiente cobertura por servicios públicos urbanos, falta de capacidad técnica y administrativa en los municipios y 4) la escasez y mala aplicación de recursos destinados a programas sociales. 
Figura 2. Marco Lógico. Problema, causas, efectos, fines, medios, líneas de acción y objetivo común. Región Otomí-Tepehua.

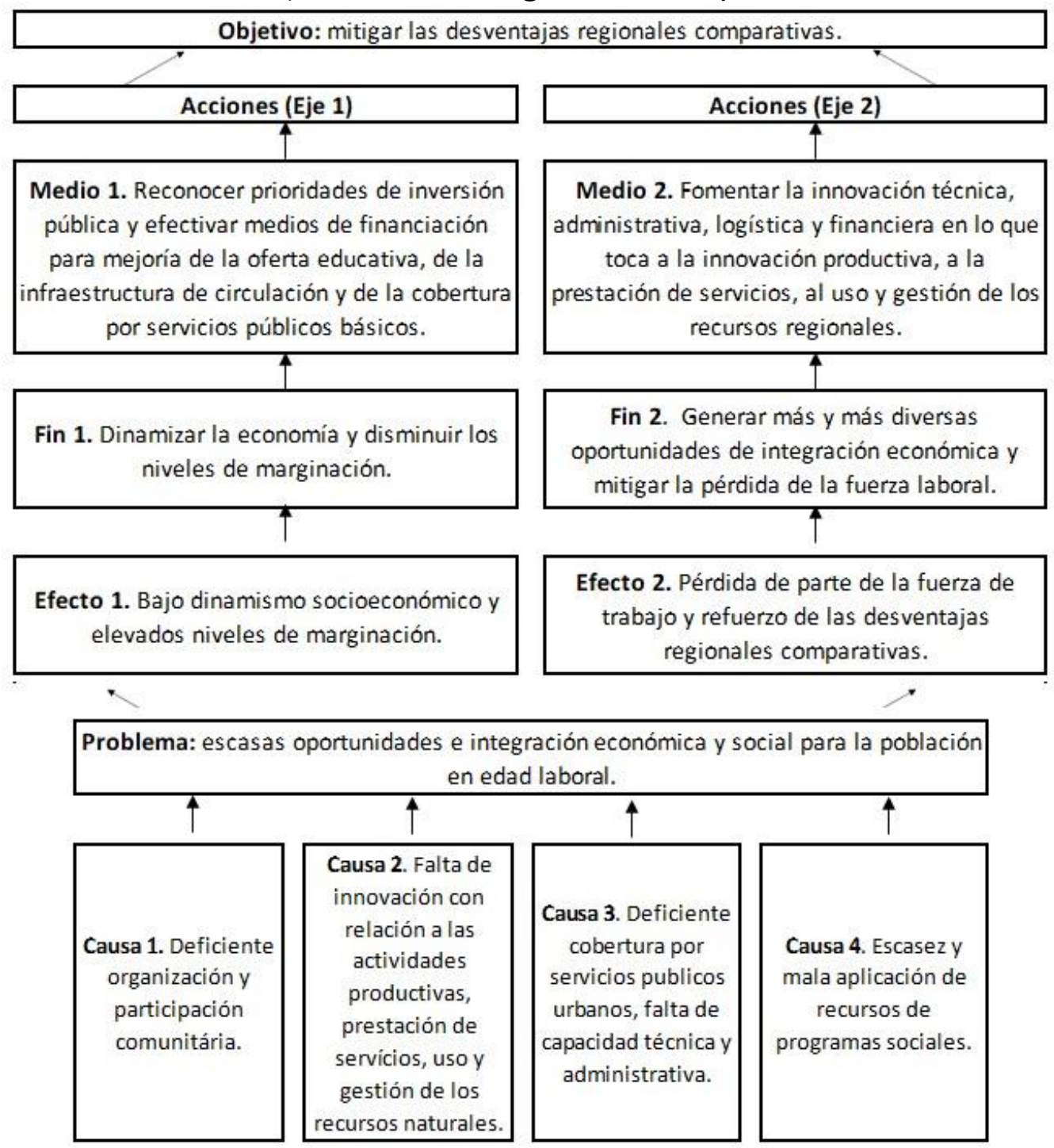

Fuente: elaboración propia a partir del diagnóstico realizado y la aplicación de la metodología del marco lógico.

Como efectos de esta problemática, se reconoce: 1) la constitución de un bajo dinamismo socioeconómico y de elevados niveles de marginación y 2) la pérdida de parte de la fuerza laboral por la emigración y el refuerzo de las desventajas regionales comparativas. A cada uno de estos efectos se relaciona un fin: 1) dinamizar la economía y disminuir los grados de marginación y 2) generar más y más diversas oportunidades de integración económica y mitigar la pérdida de la fuerza laboral.

Dichos fines están vinculados a los medios, que a su vez se vinculan con ejes de acciones: 1) reconocer prioridades de inversión pública y volver efectivas los medios de financiación para mejoría de la oferta educativa, de la infraestructura de circulación y de la cobertura por servicios públicos básicos (articulado al Eje 1); 2) fomentar la innovación técnica, administrativa, logística y financiera en lo que toca a la innovación productiva, a la prestación de servicios, al uso y gestión de los 
recursos regionales (articulado al Eje 2). Los distintos ejes de acción, en su conjunto, tienen la meta común de mitigar las desventajas territoriales comparativas.

Con relación al Eje 1, se propone las siguientes acciones:

- fomentar la participación ciudadana en la planeación y ejecución de las políticas públicas de gobierno, reconociendo las organizaciones comunitarias como entidades legitimas para establecer consensos sobre las demandas sociales prioritarias y para la identificación de recursos a ser valorados;

- establecer prioridades a nivel regional, considerando las demandas y los recursos reconocidos por los diversos sujetos presentes en la zona;

- fomentar la búsqueda por apoyo financiero y asesoría técnica juntamente al sector público a través de la adscripción a convocatorias difundidas en el ámbito de los programas de gobierno, con el fin de promover mejorías en la infraestructura vial, productiva y educativa;

- buscar apoyo, asesoría y capacitación a través de la colaboración con organizaciones no-gubernamentales, universidades y entidades supranacionales;

- emprender la búsqueda por facilidades de acceso a créditos para los productores, vislumbrándose las posibilidades de reducción de las tasas de interés.

En este ámbito, se considera que los administradores públicos deben proporcionar a las organizaciones comunitarias la asesoría técnica, financiera, jurídica y administrativa necesaria, así como la infraestructura básica requerida. Las comunidades, por su parte, deben de aportar su iniciativa y su trabajo en las tareas que les correspondan, con el fin de ofrecer una base para la participación en la planeación y ejecución de acciones jerarquizadas en forma de planes y programas públicos y comunitarios.

Con relación al Eje 2, se propone las siguientes acciones:

- la promoción de actividades productivas variadas, como la fruticultura, la acuicultura, la ganadería y la artesanía, con énfasis no solamente en productos típicos regionales, como el café de sombra y los tenangos, para que la economía se vuelva más diversificada y capaz de enfrentar períodos de crisis en la producción o comercialización de productos específicos;

- mejorar y estandarizar la calidad del producto final comercializado, de manera que se pueda enfrentar la competencia externa y las variaciones del valor de la producción en el mercado nacional e internacional;

- promocionar la comercialización de la producción regional a través del uso del marketing y de la búsqueda por nuevos mercados consumidores, tanto internos como externos;

- dar preferencia al uso de técnicas y tecnologías apropiadas a la mejoría de la productividad y a la conservación y regeneración de los ecosistemas; 
- proporcionar la formación profesional requerida a las actividades que se pretende fomentar, como el comercio exterior, el turismo, la administración pública y privada o la ingeniaría forestal, por ejemplo;

establecer zonas destinadas a diferentes usos del suelo, de acuerdo con la demanda por el desarrollo económico y las necesidades de conservación ambiental;

- promover la creación de Unidades de Manejo para la Conservación de la Vida Silvestre (UMA) y el desarrollo de actividades vinculadas, como el ecoturismo, la educación ambiental, el manejo y conservación de flora y fauna y la investigación científica, implementándose, tanto como posible, el recibimiento de pagos por servicios ambientales.

Para eso, se requieren mayores vínculos entre iniciativa privada, comunidades y universidades, con un apoyo constante del sector público, tanto en lo que concierne a la promoción de micro y pequeñas empresas como a la creación de cooperativas. Una mayor solidaridad entre diferentes agentes tiende a mejores panoramas para la inversión pública y privada, generando más adecuados contextos para la innovación organizacional y productiva, conllevando a las posibilidades de mejoría social y de conservación ambiental.

\section{Conclusiones}

En la región Otomí-Tepehua (2000-2010), se diagnosticó una pérdida de las oportunidades abiertas por la ventana de oportunidades. Más precisamente, se identificó el problema público central a ser priorizado por programas y planes de acciones: las escasas oportunidades de integración económica para la población en edad laboral. Por estar asociado a causas y consecuencias, este problema orientó la formulación de líneas de acción cuyo objetivo común es mitigar las desventajas regionales comparativas. Sin embrago, la experiencia sugiere que este es un trabajo a ser realizado a lo largo plazo, que tiene que resolverse en ámbitos menos explorados por la política pública tradicional, por lo que es necesario empoderar a las personas, a las comunidades y a las municipalidades, de acuerdo a las características de la zona, incrementándose su potencial cultural, técnico y administrativo, de abajo hacia arriba, para que estén preparados para generar recursos propios y para recibir inversión pública y privada, con el fin de promover el desarrollo territorial a partir de una perspectiva integral, participativa y sostenible.

\section{REFERENCIAS}

BELL, M.; BLAKE, M.; BOYLE, P.; WILLIAMS-DUKE, O.; REES, P.; STILLWELL, J.; HUGO, G. Cross-national comparison of internal migration: issues and measures. Journal of Royal Statistics Society, v. 3, n. 165, p. 435-464, 2002. 
BILSBORROW, R. E. Migration, urbanization, and development: new directions and issues. New York: Springer Science \& Business Media, 1998.

BRITO, F.; CARVALHO, J. A. M. de; TURRA, C. M.; QUEIRÓZ, B. L. Transição da estrutura etária e políticas sociais. In: CENTRO DE GESTÃO E ESTUDOS ESTRATÉGICOS (CGEE). Populações e políticas sociais no Brasil: os desafios da transição demográfica e das migrações internacionais. Brasilia: CGEE, 2008, p. 19-62.

BUSSO, G. Migración Interna, desventajas sociales y desarrollo en América Latina. Enfoques y discusiones sobre una relación dinámica y compleja para el uso políticas de desarrollo territorial. Veracruz: Serie Manovuelta, 2009.

CABRERA, L. A; ESPINOZA, J. M.; ZUÑIGA, C. A.; ROMERO, E. M.; MENDOZA, L. G.; LOZA, E. L. Regiones terrestres prioritarias de México. México-DF: Comisión Nacional para el Conocimiento y usos de la Biodiversidad de México, 2000.

CAMPUZANO, E. P.; CERQUERA, C. S. Tendencias recientes de la migración interna en México. Papeles de población, v. 19, n. 76, p. 53-8, 2013.

CANALES, A. Hacia una visión comprehensiva del nexo entre migración, desarrollo y derechos humanos. Migración y desarrollo, v. 9, n. 16, 43-78, 2011.

CANALES, A. Presentación. In: CANALES, A. (Org.) Panorama actual de las migraciones en América Latina. Guadalajara: Centro Universitario de Ciencias Económico Administrativas, Departamento de Estudios Regionales, Centro de Estudios de Población, 2006.

CASTLES, S.; DELGADO-WISE, R. Apuntes para una visión estratégica sobre desarrollo, migración y derechos humanos. Migración y desarrollo, v. 10, n. 18, p. 185-191, 2012.

CENSO DE POBLACIÓN Y VIVIENDA. Instituto Nacional de Estadística y Geografía (INEGI). México, DF. 2000.

CENSO DE POBLACIÓN Y VIVIENDA. Instituto Nacional de Estadística y Geografía (INEGI). México, DF. 2010.

CORTE-CRUZ, P. S.; CARRILLO-HUERTA, M. M. Impactos de políticas públicas en México. El caso de Procampo y Oportunidades en la producción de maíz, 2010. Gobierno y Desarrollo, n. 2, 2017.

DOMENACH, H.; PICOUET, M. Las migraciones. Córdoba: Dirección General de Publicaciones-UNC, 1995. 
DURAND, J.; MASSEY, D. S. Clandestinos: Migración México-Estados Unidos en los albores del siglo XXI. México-DF: Miguel Ángel Porrúa, 2003.

FONSECA, S. A. El café de sombra: un ejemplo de pago de servicios ambientales para proteger la biodiversidad. Gaceta Ecológica, n. 80, p. 19-31, 2006.

GARCÍA, O. Fracasan programas sociales porque no preguntan a beneficiaries. La silla rota de Hidalgo, Pachuca de Soto, Estados, 27 de Agosto de 2019, p. 1.

GÓMEZ, H. M.; VALTIERRA, R. R. Experiencias en la implementación del modelo de desarrollo en la región Otomí-Tepehua en el estado de Hidalgo. Pachuca de Soto: Gobierno del Estado de Hidalgo, 2005.

GÓMEZ-OLIVER, L.; TACUBA-SANTOS, A. La política de desarrollo rural en México ¿Existe correspondencia entre lo formal y lo real? Economía, v. 14 n. 42, 2017.

GÓMEZ-AÍZA, L. Percepciones acerca de la biodiversidad y de las funciones ambientales en Huehuetla (Hidalgo, México). In: GÓMEZ-AÍZA, L. (Coord.) Saberes y prácticas en torno a la salud y bienestar: manejo de recursos bióticos en la zona Otomí-Tepehua, Hidalgo. Pachuca de Soto: Lito Impresos Bernal, 2013, p. 211-231.

GÓMEZ-POMPA, A. Las raíces de la etnobotánica mexicana. Acta Biológica Panamensis, v. 1, p. 87-100, 1993.

GRANADOS, O. H. The Tuxpan river basin: a case study of the WFD as a guideline for protecting tropical river systems. In: International Conference of Environmental Engineering, 7, 2008, Lithuania. Anais... Vilnius: Faculty of Environmental Engineering Vilnius Gediminas Technical University, 2008, p. 1-8.

GUTIÉRREZ, I. E. Caminantes de la tierra ocupada: emigración campesina de la Huasteca hidalguense a las minas de Pachuca. México-DF: Consejo Nacional para la Cultura y las Artes, 1992.

HARRIS, J. R.; TODARO, M. P. Migration, unemployment and development: a twosector analysis. The American economic review, v. 60, n. 1, p. 126-142, 1970.

HERNÁNDEZ, C. Desarrollo e Injusticia ambiental: el uso de aguas negras en el Valle del Mezquital, Hidalgo, México. 2019. Tese (Doutorado en Ciências Sociais e Políticas). Universidad Iberoamericana, México-DF, 2009.

HERRERA, G. La migración vista desde el lugar de origen. Íconos-Revista de Ciencias Sociales, n. 15, p. 86-94, 2013.

HUERTA, D. M. Programas sociales fracasan por opacidad, mientras la pobreza avanza, acusan expertos. Sin Embargo. México-DF., 29 de noviembre de 2014, p. 5 . 
ÍNDICE ABSOLUTO DE MARGINACIÓN. Consejo Nacional de Población (CONAPO). México, DF. 2010.

LEE, E. S. A theory of migration. Demography, v. 3, n1, p. 47-57, 1966.

LORENZO-MONTERRUBIO, C. Los tenangos. Mitos y ritos bordados: arte textil hidalguense. México-DF: Consejo Nacional para la Cultura y las Artes, Dirección General de Culturas Populares, 2008.

LOZANO-ASCENCIO, F. Migración internacional, transición demográfica y remesas en México. Japan Center for Area Studies (JCAS), Symposium Series, N. 19, Osaka, Japón, 2003.

MANETTA, A.; LABRA-HERNÁNDEZ, L. A.; SERRANO-AVILÉS, T. La (in)capacidad de respuesta al ODS número 6 en los municipios de la zona Otomí-Tepehua (Hidalgo, México). Planeta Amazônia, n. 9, p. 159-173, 2017.

MÁRQUEZ-RAMÍREZ, G. Visión de la biodiversidad en la zona Otomí-Tepehua en las crónicas novohispanas. In: GÓMEZ-AíZA, A. (Coord.) Saberes y prácticas en torno a la salud y bienestar: manejo de recursos bióticos en la zona Otomí-Tepehua, Hidalgo. Pachuca de Soto: Lito Impresos Bernal, pp. 117-133, 2013.

MERINO, M. Los programas de subsidios al campo: las razones y las sinrazones de una política mal diseñada. Documento de trabajo 229, México-DF: CIDE-División de Administración Pública, 2009.

MÉXICO. Comisión Nacional para el Conocimiento y Uso de la Biodiversidad (CONABIO). Bosques, selvas y café de Chiapas. México-DF, 2015.

MÉXICO. Consejo Nacional de Población (CONAPO). Índice absoluto de marginación, 2000-2010. México-DF, 2013.

OLIVEIRA, O. de. Jóvenes y precariedad laboral en México. Papeles de Población, $n$. 49, p. 37-73, 2006.

ORTEGÓN, E.; PACHECO, J. F.; PRIETO, A. Metodología del marco lógico para la planificación, el seguimiento y evaluación de proyectos y programas. Santiago de Chile: CEPAL-ILPES, Serie Manuales, no. 42, 2005.

PARTIDA-BUSH, V. La transición demográfica y el proceso de envejecimiento en México. Papeles de Población, v. 11, n. 45, p. 9-27, 2005.

PÉREZ, S. L. De lo global a lo local: cambios de cultivos y estrategias de sobrevivencia ante la crisis del mercado internacional de café. El caso de la sierra Otomí-Tepehua en el estado de Hidalgo. Problemas del desarrollo, v. 33, n. 131, 2002.

RAFFESTIN, C. Por uma geografia do poder. Campinas: Ática, 1993. 
RAMÍREZ-BAUTISTA, A.; SÁNCHEZ-GONZÁLEZ, A.; SÁNCHEZ-ROJAS, G.; CUEVASCARDONA; C. (Eds.). Biodiversidad del estado de Hidalgo. Tomos I y II. Pachuca de Soto; UAEH/CONACyT, 2017.

RODRÍGUEZ, E. Juventud y desarrollo en América Latina: desafíos y prioridad en el comienzo de un nuevo siglo. In: PIEEK, E. Los jóvenes y el trabajo. La educación frente a la exclusión social, México-DF: CONALEP, 2001.

RODRÍGUEZ-VIGNOLI, J. Distribución espacial de la población de América Latina y el Caribe: tendencias, interpretaciones y desafíos para las políticas públicas. Serie Población y Desarrollo, no. 32, 2002.

RODRÍGUEZ-VIGNOLI, J.; BUSSO. Migración interna y desarrollo en América Latina entre 1980 y 2005: un estudio comparativo con perspectiva regional basada en siete países. New York: United Nations Publications, 2009.

ROMO, A. G.; PEREZ, S. L. Café y pobreza en los productores Otomí-Tepehua: crisis del desarrollo rural frente al neoliberalismo. CIMEXUS, n, 2, v. 13, p. 27-42, 2018.

RUIZ-CHAPETO, C. Población y migraciones rurales en México. Hipótesis de otro siglo. Economía, sociedad y territorio, n. 6, v. 2, p. 239-258, 2014.

SALAZAR-ORTIZ, C. Y.; SILVA; M. T. P.; BASURTO-PEÑA, F. A. Aporte a los sistemas de producción de café a la salud y el bienestar de los pobladores de Huehuetla, Hidalgo. In: GÓMEZ-AíZA, A. (Coord.) Saberes y prácticas en torno a la salud y bienestar: manejo de recursos bióticos en la zona Otomí-Tepehua, Hidalgo. Pachuca de Soto: Lito Impresos Bernal, pp. 237-250, 2013.

SÁNCHEZ-VÁZQUEZ, S. Enfermedades culturales, especialistas rituales y prácticas terapéuticas en la región Otomí-Tepehua. In: GÓMEZ-AÍZA, A. (Coord.) Saberes y prácticas en torno a la salud y bienestar: manejo de recursos bióticos en la zona Otomí-Tepehua, Hidalgo. Pachuca de Soto: Lito Impresos Bernal, pp. 295-328, 2013.

SANTOS, M. A natureza do espaço: técnica e tempo, razão e emoção. Hucitec: São Paulo, 1996.

SUBIRATS, J.; KNOEPFEL, P.; LARRUE, C.; VARONE, F. Análisis y gestión de las políticas públicas. Barcelona: Ariel, 2008.

TORRES, F.; ROJAS, A. Política Económica y Política Social en México: desequilibrio y saldos. Problemas del Desarrollo, V. 46, n. 182, p. 41-66, 2015.

VARGAS-GONZÁLEZ, P. Pobreza, migración y desempleo: mujeres en la región Otomí-Tepehua de Hidalgo. Nueva Antropología, v. 24, n. 75, p. 93-109, 2011. 
VÁZQUEZ-SANDRÍN, G. Diagnóstico Participativo de las poblaciones indígenas del estado de Hidalgo. Hacia la conformación de un Programa Estatal de Población Indígena. Pachuca de Soto: UAEH. 2018.

VILLAVICENCIO-NIETO, M. Á.; PÉREZ-ESCANDÓN, B. E. Vegetación e inventario de la flora útil de la Huasteca y la zona Otomí-Tepehua de Hidalgo. Ciencia Universitaria, no. 1, p. 23-33, 2010.

Alex Manetta. Profesor-investigador del Instituto de Ciencias Sociales y Humanidades de la Universidad Autónoma del Estado de Hidalgo.. E-mail alexmanetta@hotmail.com

Tomás Serrano Avilés. Profesor-investigador del Área Académica Demografía y Sociología, Instituto de Ciencias Sociales y Humanidades, Universidad Autónoma del Estado de Hidalgo. E-mail tomascongreso@hotmail.com

Como citar: MANETTA, Alex; AVILÉS, Tomás Serrano. Desigualdades territoriales y migración: consecuencias sociodemográficas y lineamientos de acciones para la región Otomí-Tepehua (Hidalgo, México). Redes (St. Cruz Sul, Online), Santa Cruz do Sul, v. 25, p. 1787-1811, nov. 2020. ISSN 1982-6745. doi:https://doi.org/10.17058/redes.v25i4.14564.

\section{CONTRIBUIÇÃO DE CADA AUTOR}

Conceituação: Alex Manetta.

Curadoria de Dados: Alex Manetta.

Análise Formal: Alex Manetta.

Obtenção de Financiamento: Alex Manetta e Tomás Serrano Avilés.

Investigação/Pesquisa: Alex Manetta e Tomás Serrano Avilés.

Metodologia: Alex Manetta e Tomás Serrano Avilés.

Administração do Projeto: Alex Manetta.

Recursos: Alex Manetta.

Validação: Alex Manetta.

Visualização: Alex Manetta.

Escrita - Primeira Redação: Alex Manetta.

Escrita - Revisão e Edição: Alex Manetta.

Fuente de financiamiento: Secretaría de Educación Pública (SEP, México). 